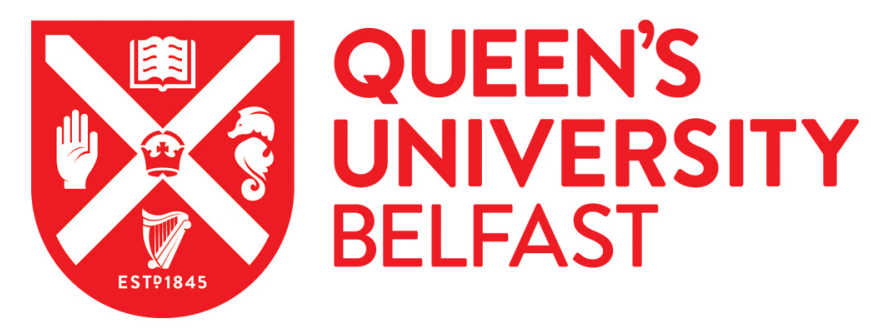

\title{
An Evaluation of a Storybook Targeting Parental Attitudes, Intention, and Self-Efficacy to Change Their Child's Oral Health Behavior
}

O'Malley, L., Adair, P., Burnside, G., Robinson, L., Coffey, M., \& Pine, C. (2017). An Evaluation of a Storybook Targeting Parental Attitudes, Intention, and Self-Efficacy to Change Their Child's Oral Health Behavior. Health Psychology, 36(2), 152-159. https://doi.org/10.1037/hea0000428

Published in:

Health Psychology

Document Version:

Peer reviewed version

Queen's University Belfast - Research Portal:

Link to publication record in Queen's University Belfast Research Portal

Publisher rights

Copyright 2017 APA. This work is made available online in accordance with the publisher's policies. Please refer to any applicable terms of use of the publisher.

\section{General rights}

Copyright for the publications made accessible via the Queen's University Belfast Research Portal is retained by the author(s) and / or other copyright owners and it is a condition of accessing these publications that users recognise and abide by the legal requirements associated with these rights.

Take down policy

The Research Portal is Queen's institutional repository that provides access to Queen's research output. Every effort has been made to ensure that content in the Research Portal does not infringe any person's rights, or applicable UK laws. If you discover content in the Research Portal that you believe breaches copyright or violates any law, please contact openaccess@qub.ac.uk. 


\section{Copyright Notice:}

This paper is a draft of the paper that is published in Health Psychology (http://www.apa.org/pubs/journals/hea/)

This article may not exactly replicate the final version published in the APA journal. It is not the copy of record. The final version of this paper can be found at: http://psycnet.apa.org/index.cfm?fa=search.displayRecord\&id=62649669-C413$\underline{\text { AF2B-2FAD-C169B4E6E24B\&resultID=1\&page=1\&dbTab=pa\&search=true }}$

An evaluation of a storybook targeting parental attitudes, intention and selfefficacy to change their child's oral health behaviour

May 2016

Lucy O’Malley*

School of Dentistry, University of Manchester, UK

Pauline Adair

School of Psychological Sciences and Health, University of Strathclyde, UK

Girvan Burnside

Department of Biostatistics, University of Liverpool, UK

Louise Robinson

Salford Royal NHS Foundation Trust, Salford, UK

Margaret Coffey

School of Health Sciences, University of Salford, UK

Cynthia Pine

Barts and the London School of Medicine and Dentistry, Queen Mary University of London, UK

*Corresponding author Lucy O’Malley, School of Dentistry, Faculty of Medical and Human Sciences, University of Manchester, Oxford Road, Manchester, M13 9PL lucy.omalley@manchester.ac.uk 


\section{ABSTRACT}

Objective: Methods for reducing dental disease have traditionally focused on health education rather than targeting psychosocial determinants of the core behaviours through behaviour change strategies. This study tested a novel intervention in the form of a children's story (Kitten's First Tooth) embedded with behaviour change techniques (Abraham and Michie, 2008) with the aim of investigating how effective the intervention was at improving parents' efficacy and intention to enact oral health behaviours for their child Methods: A controlled before and after study conducted in a deprived area of England ( $n=149$; child mean age 4 years) with an intervention and control group. Changes in task specific parental self-efficacy (PSE) and intention were measured using the Oral Health Behaviours Questionnaire (OHBQ; Adair et al., 2004) at baseline and 3 months following intervention. Results: Of the 149 participants, 129 returned both baseline and evaluation questionnaires (retention 86.6\%), 125 of these pairs of questionnaires were used in the analysis (83.4\%). The OHBQ was analysed using a general linear model (ANCOVA). A significant difference was found in favour of the intervention group for PSE related to child tooth brushing behaviours $\left(\mathrm{F}_{(1,1)}=12.04, p=0.001\right)$, however no change was observed for PSE related to control of dietary sugars. Conclusions: A theorized children's story can be effective as an oral health promotion intervention by supporting parents to improve their child's oral health-related behaviour. Change was observed for child tooth brushing but not sugar control. This may reflect story contents or may be indicative of difficulties of changing dietary behaviour.

5 Key words: oral health behaviours; child oral health; behaviour change techniques; storybook; parental self-efficacy 


\section{INTRODUCTION}

Considering the potentially serious biological and psychosocial effects of tooth decay, it is striking that it is for the most part, completely preventable (Edelstein, 2006) if the correct health behaviours are in place. In an otherwise healthy child, tooth decay can be controlled through the restriction of foods and drinks which are high in sugar (noncomplex carbohydrates) and the maintenance of a daily oral hygiene routine which includes the application of fluoride toothpaste twice daily (Harris, Nicoll, Adair, \& Pine, 2004; Marinho, Higgins, Logan, \& Sheiham, 2009; Walsh et al., 2010).

Therefore, health behaviour change interventions focused on these behaviours may be important for improving child oral health outcomes.

Health promotion, usually taking the form of educational programmes, has for a number of years attempted to improve dental health related behaviours and consequently childhood dental health outcomes through increasing knowledge. A systematic review (Kay \& Locker, 1998), examined 164 experimental studies (including 36 RCTs and 80 controlled studies) testing oral health promotion for improvements in dental hygiene or dental health outcomes. This review found that oral health promotion generally resulted in improvements in knowledge but not in associated behaviours and dental health outcomes. A more recent Cochrane review of primary school-based promotion programmes for the prevention of tooth decay (Cooper et al., 2013) has confirmed Kay and Locker's findings. This review of four RCTs found insufficient evidence to show that such programmes were able to impact upon children's oral health-related behaviours in the long term.

A large international study ( $\mathrm{n}=2822)$ developed and utilised a theory based psychometric assessment measuring parents’ attitudes towards oral health related 
behaviours for their three to four year old children including dental hygiene, sugar snacking and dental attendance. Dental examination of the children was also carried out. Logistic regression showed that parents' attitudes towards the behaviours themselves and parental self-efficacy (PSE) related to dental hygiene and sugar snacking were significant predictors of the development of tooth decay in their children (Adair, Pine, Burnside, \& et al., 2004). Attitudes towards prevention were not found to be significant. This international study collected data from 17 countries and findings were consistent across ethnic groups.

Education alone may change health related knowledge which may in turn influence attitudes towards prevention but will not likely influence attitudes towards the behaviours themselves, nor is it likely to have much impact on PSE for carrying out these behaviours (Adair et al., 2004). Therefore to improve the effectiveness of health promotion for children's oral health, these behavioural factors should be incorporated into future programmes alongside education. This calls for a theory based approach to health promotion that is delivered using techniques that can impact on oral health preventive behaviours. Social cognitive theory, with a focus on parental self-efficacy, is key to understanding and predicting oral health behaviour change (Nilsen, Roback, Broström, \& Ellström, 2012; Schwarzer, Antoniuk, \& Gholami, 2015). Additionally, a theory-based approach aids the description of the active ingredients of interventions providing transparency. This is something which is rapidly being promoted and encouraged (Prestwich et al., 2014).

Furthermore, it is critical that such interventions are robustly evaluated. Testing interventions that have been developed using theory can improve understandings of which mechanisms (or combination of mechanisms) are important for affecting particular behaviours (Adair, Pine, \& Burnside, 2013; Michie, 2008). Even where 
evaluations show interventions not to be effective in their aims, important questions can be formed around the reasons why the intervention failed or had unexpected results and these can help to inform future research directions The intervention evaluated here is called 'Kitten’s First Tooth' and is a children's story embedded with specific behaviour change techniques (BCTs) (Abraham \& Michie, 2008a), evaluation of which will help inform as whether these (as a set) are important for promoting positive oral health behaviours in this population. The relationship between attitudes, intentions and self-efficacy has been supported in previous oral health research. Specifically, parental attitudes and perceived self-efficacy for oral health behaviours is an important focus for behaviour change given this has been found to differentiate between children with and without tooth decay as well as deprived versus nondeprived families in a previous international study (Adair et al., 2004). In addition, parental perceptions of risk for their child's oral health is key to future behaviour change and there is evidence from the general literature to support this (Sheeran, Harris, \& Epton, 2014).

Moreover, what this evaluation will add is insight into the utility of children's stories to convey oral health promotion messages to parents as this evidence is currently lacking. Through examination of change (or no change) in parent's attitudes, intentions and self-efficacy, an understanding of whether the intervention is able to affect the psychosocial determinants of behaviour may be possible. Further to this, an idea of the acceptability of this type of intervention for parents will be sought in terms of its use in the home. Answering these questions may help to inform future iterations of Kitten’s First Tooth, development of similar storybooks and behaviour change intervention development in the area of child oral health promotion more generally. 
The aim of this study was to evaluate the effectiveness and acceptability of Kitten's First Tooth using a non-randomised comparative study design. The story aimed to improve 1) parents' task specific self-efficacy for a key oral health behaviour: tooth brushing, with two other behaviours, sugar snacking and child dental attendance addressed to a lesser extent, 2) parents' intention to enact all 3 oral health behaviours and 3) attitude and risk perception for dental attendance.

\section{METHODS}

\section{Design}

Ethical approval for this study was granted by the University of Salford, UK. The intervention was evaluated by parents in relation to their children. A controlled before and after study design was applied resulting in two groups - Group 1 (intervention) who received a storybook and DVD (Kitten's First Tooth) and Group 2 (Control) who did not receive any intervention. The control group was a wait list control group meaning that the intervention was provided to them following the collection of outcome data. Assignment to study group was based on where participants were located, those living in one area of the city were assigned to the intervention group, and those living in another area were assigned to the control group.

Participants: All primary schools in the areas of study were contacted and asked to help facilitate the study. Seven of the 12 schools responded positively to this request. All parents of 3-5 year old children attending these schools were invited to take part in the study. Approximately 468 parents were invited to the study, with uptake being 149 (31.84\%). The size of this sample was the result of inviting all eligible participants to the study. Two areas within this city were selected for study. These areas represented similar populations but lay at opposite ends of the city. 
Geographical distance was planned in order to limit the possibilities of contamination. The literature demonstrates a consistent association between dental health and SES (Bernabe, Delgado-Angulo, \& Murasko, 2012; Du, Luo, \& Zeng, 2007; Dye, Arevalo, \& Vargas, 2010; Ferreira, Beria, \& Kramer, 2007; Reisine \& Psoter, 2001; Tanaka, Miyake, Sasaki, \& Hirota, 2013; Telford, Coulter, \& Murray, 2011; Watt, 2007). Therefore, the areas of study were matched as much as practically possible on SES. The study was conducted within a city located in North West England with higher than average levels of social and material deprivation (IMD 2010 score 35 compared to 21.67 nationally) and a largely homogenous ethnic population (94\% White).

Materials: The story, Kitten's First Tooth was provided to participants in the intervention group in two formats to improve exposure, an animation on a DVD including an audio of the story and a hardcopy of the storybook. The story was produced by an animation company specialising in children's stories and the process was guided by a consultation group of clinical and behavioural experts. Behaviour change techniques (Abraham \& Michie, 2008) were embedded into the script, these can be seen in Table 1, which gives examples of these techniques and how they appeared in the story. Further detail on the development and content of Kitten's First Tooth has been written elsewhere (O’Malley, 2013). Materials are available freely to download from the University of Manchester repository: http://bit.ly/2eUj6Em 
Table 1. Behaviour change techniques (BCT) present in the story Kitten's First

Tooth. These BCTs are based on a taxonomy (Abraham and Michie 2008)

\begin{tabular}{|c|c|c|}
\hline $\begin{array}{l}\text { BCT } \\
\text { number* }\end{array}$ & BCT & Example text \\
\hline 1 & $\begin{array}{l}\text { Provide general } \\
\text { information on the } \\
\text { behaviour health } \\
\text { link }\end{array}$ & $\begin{array}{l}\text { "Teeth are helpful to chew healthy foods. They also } \\
\text { help us have a bright smile when we keep them } \\
\text { clean with our toothbrush and toothpaste." } \\
\text { "Clean your teeth for a bright smile” }\end{array}$ \\
\hline 2 & $\begin{array}{l}\text { Provide } \\
\text { information on } \\
\text { consequences }\end{array}$ & $\begin{array}{l}\text { Owl tells cat and kitten to keep kitten's mouth } \\
\text { clean so that the new teeth can grow to be as } \\
\text { healthy as his first one }\end{array}$ \\
\hline 3 & $\begin{array}{l}\text { Provide } \\
\text { information about } \\
\text { other's approval }\end{array}$ & $\begin{array}{l}\text { "Owl is sitting next to kitten and tells him how } \\
\text { good he was today when he visited her in the } \\
\text { dental surgery" } \\
\text { "Owl is very pleased with Kitten" } \\
\text { "Owl is pleased with Cat and Kitten and tells } \\
\text { them to come back and see her soon" }\end{array}$ \\
\hline 4 & $\begin{array}{l}\text { Prompt intention } \\
\text { formation }\end{array}$ & $\begin{array}{l}\text { "Owl is sitting next to kitten and tells him how good } \\
\text { he was today when he visited her in the dental } \\
\text { surgery today Kitten says he will brush his teeth } \\
\text { tonight" }\end{array}$ \\
\hline 6 & $\begin{array}{l}\text { Provide general } \\
\text { encouragement }\end{array}$ & $\begin{array}{l}\text { Owl is sitting next to kitten and tells him how good } \\
\text { he was today when he visited her in the dental } \\
\text { surgery. }\end{array}$ \\
\hline 8 & Provide instruction & $\begin{array}{l}\text { "She says Cat should help Kitten to brush his } \\
\text { teeth" - instructs that Kitten should be helped by } \\
\text { Cat (though further instructional detail is not given) } \\
\text { "Cat is standing behind kitten helping him to } \\
\text { brush" }\end{array}$ \\
\hline 9 & $\begin{array}{l}\text { Model/ } \\
\text { Demonstrate } \\
\text { behaviour }\end{array}$ & $\begin{array}{l}\text { Dental attendance is modelled, as is Cat helping } \\
\text { Kitten to brush his teeth. Intentions that are formed } \\
\text { are carried out, e.g. tooth brushing in the final } \\
\text { scenes. }\end{array}$ \\
\hline 13 & $\begin{array}{l}\text { Provide feedback } \\
\text { on performance }\end{array}$ & $\begin{array}{l}\text { "the new teeth can grow to be as healthy as his first } \\
\text { one" - This line implies that Cat and Kitten have } \\
\text { been looking after Kitten's mouth sufficiently so far } \\
\text { - they should continue this good behaviour. }\end{array}$ \\
\hline 15 & $\begin{array}{l}\text { Teach to use } \\
\text { prompts/ cues }\end{array}$ & $\begin{array}{l}\text { "brush his teeth every morning and every night } \\
\text { and not eat sweet things at night time" } \\
\text { encouraging time of day as a prompt. }\end{array}$ \\
\hline 20 & $\begin{array}{l}\text { Plan social } \\
\text { support/ social } \\
\text { change }\end{array}$ & $\begin{array}{l}\text { "Cat is very happy that Owl and Mouse were so nice } \\
\text { to Kitten she will take him for a dental check up } \\
\text { again soon again" This BCT appears only in the } \\
\text { storybook and not in the animation. }\end{array}$ \\
\hline
\end{tabular}

*BCT number refers to the number given to the technique within the taxonomy (Abraham and Michie 2008) 
Procedure: The intervention (Kitten’s First Tooth), was applied in one geographical area and data was collected from participants in that area as well as from participants in a matched geographical area, which acted as a control. Schools were identified as an appropriate and reliable route through which to engage children and parents in health promotion (Kwan, Petersen, Pine, \& Borutta, 2005).

Each of the schools in the areas of study were contacted and asked to help facilitate the study. Schools sent the study information (including the information sheet, consent form and baseline questionnaires) home via the pupils to all eligible parents $(n=468)$. This process was repeated three times in order to maximise responses. Participants were enrolled in the study when they returned completed consent forms to the research team (either directly by freepost or via the school); at the same time, participants returned baseline questionnaires. Participants in the intervention group were subsequently sent intervention packs via the schools. The pack consisted of the animation on a DVD, the storybook, a fridge magnet and a bookmark. Parents were advised to use the DVD and storybook regularly (3 or more times per week).

After 3 months, the final questionnaires were distributed to all participants. This questionnaire drop was carried out three times in order to retain as many participants as possible. All participants also received a 'thank you' end of study pack upon returning their completed questionnaires. This pack consisted of a Kitten's First Tooth themed brushing chart with stickers and oral health themed stationary. At study end, the participants in the control group received the animation and storybook.

Measurements: A demographic questionnaire was used to collect descriptive data from participants at baseline. Information collected included the age of the child and the parent, ethnicity and levels of parents' education. The Oral Health Behaviours 
Questionnaire (OHBQ) was used to collect baseline and outcome data. The OHBQ (Adair, Pine, Burnside, \& et al., 2004), was developed to measure attitudes and beliefs of parents around their child's dental health and takes around ten minutes to complete. The measure is made up of eight sub-scales, with three of these being grouped as parental attitudes toward child tooth brushing behaviour (i.e. importance and intention to brush child's teeth, parental efficacy in relation to child tooth brushing, attitudes toward prevention), two grouped as parental attitudes towards child sugar snacking (i.e. importance and intention to control child sugar snacking, parental efficacy in relation to controlling child sugar snacking) and three grouped as parental attitudes towards dental decay (i.e. perceived seriousness of tooth decay in children, chance control - decay occurs by chance, external control - preventing decay is the dentist's responsibility). Reliability of these sub-scales was found to be reasonably good with Cronbach's $\alpha$ for the sub-scales ranging from $0.51-0.81$ (six of the sub-scales $>0.6$ ) (Adair et al., 2004).

The OHBQ was adapted to include items relating to intention to take the child to asymptomatic dental appointments as well as outcome expectancy for dental appointments. These items underwent face validity testing by health psychologists and parents. Intention for each of the three oral health behaviours was measured. Task specific PSE was measured for both tooth brushing and sugar snacking. Outcome expectancy for oral health behaviours, risk perception and PSE for preventing dental disease were also measured.

Additionally, evaluation questions were added to the questionnaire. These were sent to the participants in the intervention group only, at the end of the study in order to establish acceptability of the intervention. Questions were specifically worded around Kitten's First Tooth and can be seen in Table 2. The six non-validated items asked 
related to the practicality of the book and were simple stand-alone questions. The answer format was a on a 5-point likert scale (1, being a negative response and 5 positive). Three open questions were asked around the parent preference (for the DVD, the book or no difference) and around child understanding of the story (which of the characters their child liked, and what message stood out from the story).

Analysis: Data was entered directly into SPSS and each entered case was double checked with the questionnaire to control for data entry errors. Descriptive statistics, including frequencies for nominal or ordinal data and means for continuous data were generated to check for outliers. Where outliers were found, the original questionnaires were checked against the database.

Data collected using the OHBQ was analysed according to the original eight factor structure (Adair et al., 2004). The additional items were considered separately. Scale means were calculated for each of the subscales. The normality of the scale data was determined by reviewing the skewness and kurtosis. The scale data from the OHBQ was analysed using a general linear model (ANCOVA) whereby the dependant variable was the mean score at post intervention and the baseline score was entered into the model as a covariate. The comparison was made between the groups (intervention and control). This analysis allowed for a between groups comparison of the mean scores following the intervention while adjusting for the baseline mean scores. All tests were carried out using SPSS version 20 (IBM Corp, 2011). 


\section{RESULTS}

Of the total 149 participants (intervention group n=93; control group n=56), 129 returned both baseline and evaluation questionnaires (retention of 86.6\%), 125 of these pairs of questionnaires were used in the analysis (83.4\%). Four questionnaires were not used due to substantial missing data. Participant flow can be seen in Figure

\section{Figure 1: Participant flow diagram}

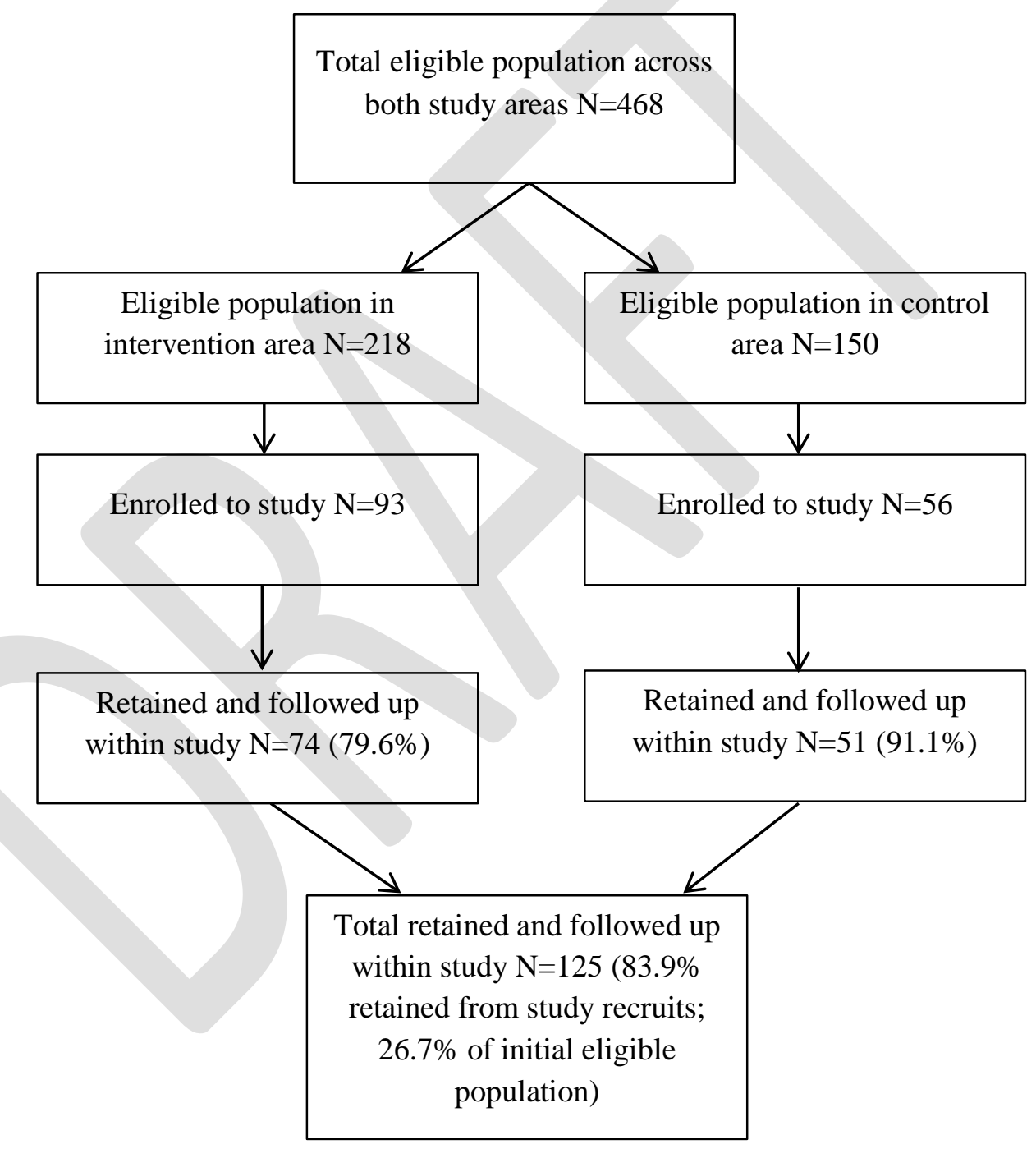

Participant characteristics: The mean age of the children at the start of the study was just under 4 years (3.9 years in the intervention and 3.8 years in the control 
groups), 53\% were female. Across both groups, parents reported that $73.5 \%$ of children had visited a dentist (72.5\% intervention; $74.5 \%$ control). Less than half (44\%) of the parents in the intervention group reported that they attended the dentist regularly, compared to two thirds (66\%) of parents in the control group. There was no significant difference between groups for either mothers' educational level $\left(\mathrm{X}^{2}=\right.$ $0.24 \mathrm{df} 1 \mathrm{p}=0.63)$ or fathers' $\left(\mathrm{X}^{2}=2.96 \mathrm{df} 1 \mathrm{p}=0.09\right)$.

Reliability of measure: Reliability of the eight subscales of the OHBQ and the 3 additional scales was assessed using Cronbach’s alpha. The majority of scales were shown to have acceptable or good levels of reliability (0.6-0.9). However, the alpha statistic for subscale 3 of the OHBQ (attitudes towards prevention) was lower at 0.58 and therefore is to be interpreted with caution. Sub-scale 8 of the OHBQ (external control) was 0.44 so was excluded from further analysis. Reliability for intention to attend dental visits was low (0.49 so this scale was not used in analysis. Instead the results for the two intention items were used separately in the analysis. 
Task specific parental self-efficacy: Regarding PSE for child tooth brushing behaviour, the post intervention mean scores were compared between the intervention and the control groups adjusting for baseline scores (Table 3). Comparison showed there to be a significant effect with regard to PSE for child tooth brushing in favour of the intervention $\left(\mathrm{F}_{(1,1)}=12.04, p=0.001\right)$. However, assessment of the intervention for PSE related to child sugar snacking showed no significant difference $\left(F_{(1,1)}=3.34\right.$, $p=0.07)$.

Behavioural intention: In terms of intention to enact tooth brushing behaviour, a statistically significant difference between the groups was found in favour of the intervention $\left(\mathrm{F}_{(1,1)}=11.61, p=0.01\right)$. This is somewhat supported by parents' reported intentions for tooth brushing related to the use of Kitten's First Tooth in that the scale mean was greater than 3 (Likert scale was 1-5) seen in Table 2.

Regarding parents’ intention to control child sugar snacking behaviours, no significant difference could be identified between the groups following the intervention $\left(\mathrm{F}_{(1,1)}=2.71, p=0.102\right)$. Based on these results it could be said that the intervention did not affect parents' intention to enact this behaviour.

The two item subscale pertaining to intention to take the child to the dentist was not shown to have sufficient reliability to be presented as a scale. These items were added to the OHBQ as additional questions and had not been previously validated. The scores for the individual items are instead presented in Table 3.

For the first item ('I plan to take my child to the dentist in the next 6 months'), comparison at post intervention (adjusted for baseline scores), showed there to be a statistically significant change in favour of the intervention $\left(F_{(1,1)}=18.93, p<0.001\right)$. Looking at the mean scores for this item, it can be seen that while the score for the 
control group was initially higher than that of the intervention group, at post intervention the score had dropped. Over the same time period the mean score for the intervention group increased. For the second item ('I have made an appointment to take my child to the dentist soon'), a significant difference was found between the groups, which again, favoured the intervention $\left(\mathrm{F}_{(1,1)}=11.21, p=0.001\right)$.

Parental attitudes: In terms of parents' attitudes towards tooth brushing as a preventive method, a statistically significant difference was observed between the intervention and the control group $\left(\mathrm{F}_{(1,1)}=6.70, p=0.011\right)$ in favour of the intervention. The mean values are shown in Table 3.

General parental attitudes towards tooth decay were measured using two subscales of the OHBQ (the mean scores of which are both shown in Table 3). For the subscale 'perceived seriousness of tooth decay', a between groups comparison following the intervention showed a statistically significant difference in favour of the intervention $\left(F_{(1,1)}=17.31, p<0.001\right)$. Whereas for the subscale 'chance control', no statistically significant difference was found between groups $\left(\mathrm{F}_{(1,1)}=3.47, p=0.065\right)$.

Items pertaining to outcome expectancy for dental attendance found a statistically significant difference between the intervention and control group in favour of the intervention $\left(\mathrm{F}_{(1,1)}=8.67, p=0.004\right)$.

The evaluation questions relating to outcome expectancy for dental attendance gave a mean score of 3.79 (SD 0.84), indicating that parents agreed that their outcome expectancies were improved as a result of the intervention. 
Table 2. Acceptability of Kitten's First Tooth among the intervention parents

\begin{tabular}{|c|c|c|}
\hline \multicolumn{2}{|l|}{ Item } & $\begin{array}{l}\text { Mean score } \\
\text { (SD)* }\end{array}$ \\
\hline \multicolumn{2}{|c|}{ Kitten’s First Tooth made it easier for me to read with my child } & $4.11(0.68)$ \\
\hline \multicolumn{2}{|c|}{ My child understood the content of Kitten's First Tooth } & $4.31(0.53)$ \\
\hline \multicolumn{2}{|c|}{$\begin{array}{l}\text { Kitten's First Tooth helped me to talk to my child about sweet foods } \\
\text { and drinks }\end{array}$} & $4.14(0.60)$ \\
\hline \multicolumn{2}{|c|}{$\begin{array}{l}\text { Kitten's First Tooth helped me to talk to my child about going to the } \\
\text { dentist }\end{array}$} & $4.26(0.74)$ \\
\hline \multicolumn{2}{|c|}{$\begin{array}{l}\text { Kitten's First Tooth helped me to talk to my child about brushing } \\
\text { his/her teeth }\end{array}$} & $4.2(0.72)$ \\
\hline \multicolumn{2}{|c|}{$\begin{array}{l}\text { It was easy to fit reading the Kitten's First Tooth into my child's } \\
\text { routine }\end{array}$} & $4.11(0.68)$ \\
\hline & 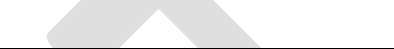 & $\%(\mathrm{n})$ \\
\hline \multirow[t]{3}{*}{ Parent preference regarding format $(\mathrm{n}=34)$} & For DVD & $52.9 \%(18)$ \\
\hline & For book & $32.4 \%(11)$ \\
\hline & No difference & $14.7 \%(5)$ \\
\hline \multirow[t]{3}{*}{ Child preference for story character $(\mathrm{n}=19)$} & Kitten & $15(78.9 \%)$ \\
\hline & Owl & $3(15.8 \%)$ \\
\hline & All of them & $1(5.3 \%)$ \\
\hline \multirow[t]{4}{*}{ Stand out message from the story $(n=24)$} & $\begin{array}{l}\text { how to brush teeth/ } \\
\text { tooth brushing } \\
\text { generally }\end{array}$ & $13(54.2 \%)$ \\
\hline & $\begin{array}{l}\text { importance of oral } \\
\text { health }\end{array}$ & $5(20.8 \%)$ \\
\hline & $\begin{array}{l}\text { not to be afraid of the } \\
\text { dentist/ visit dentist } \\
\text { regularly }\end{array}$ & $4(16.7 \%)$ \\
\hline & limit sugar & $2(8.3 \%)$ \\
\hline
\end{tabular}

*Scale rating from strongly disagree (1) - strongly agree (5) 
Table 3. Mean scores on the Oral Health Behaviours Questionnaire and additional items and results of ANCOVA analysis

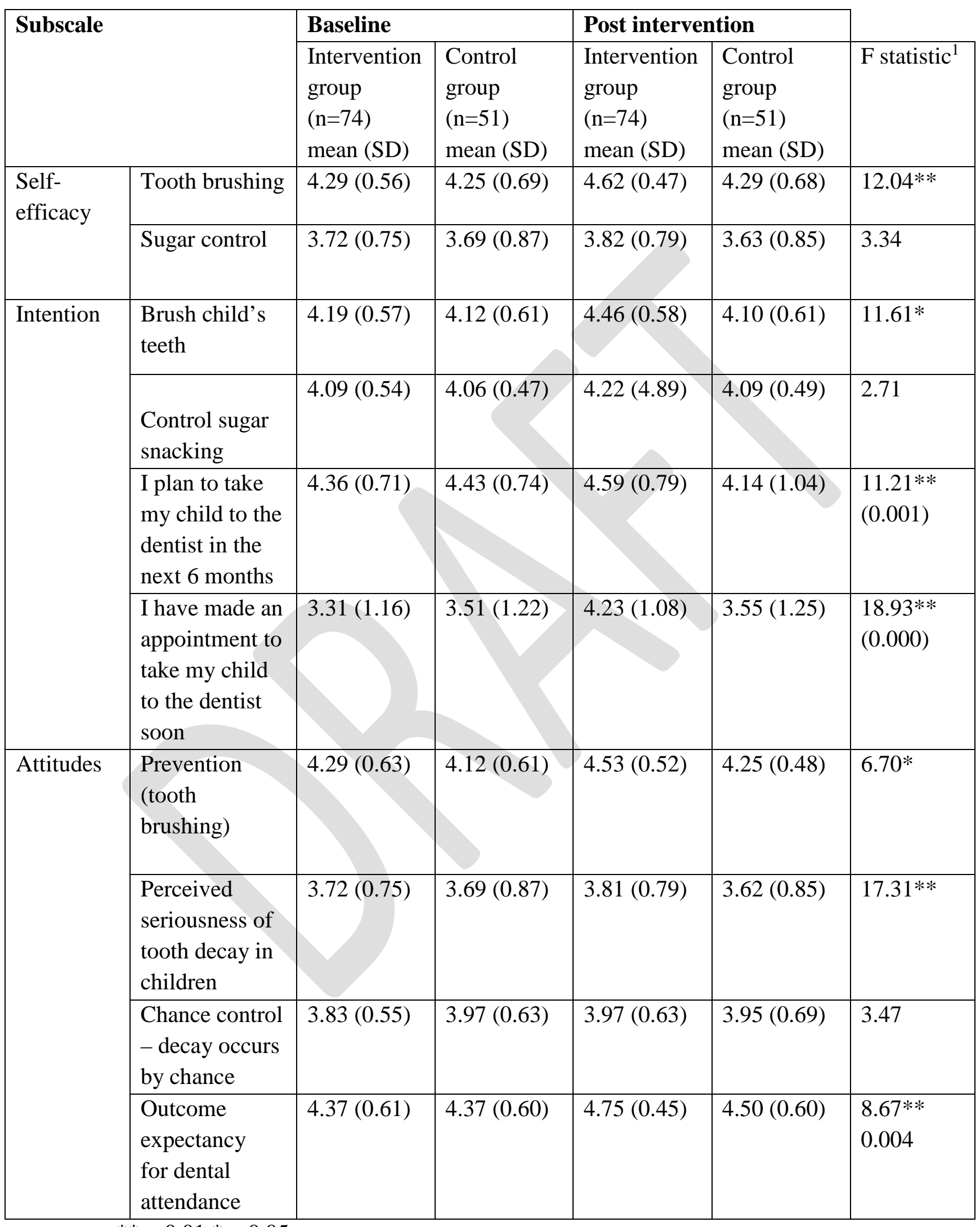

$* * p<0.01 * p<0.05$

${ }^{1}$ Between group comparison post intervention having adjusted for baseline scores (ANCOVA) All baseline scores were significantly related to post intervention scores 
Acceptability of Kitten's First Tooth to parents: Parents acceptability of Kitten's

First Tooth was assessed. The mean scores indicate that parents felt that their children understood the content of the story. They also felt that they could easily fit it into their bedtime routine. This data is presented in Table 2 . The scores also indicated that parents agreed that the story served as a prompt for them to engage in conversation with their child about tooth brushing, sugar snacking and dental attendance. In terms of parent reported preference for format, 34 responses were collected with slightly more preferring the DVD $18(n=18,52.9 \%)$ than the book $(n=11,32.4 \%)$. Five parents (14.7\%) reported no difference in terms of preference. Nineteen responses were collected pertaining to the child's favourite character with 15 of these reporting the kitten character to be the favourite (3 opted of the owl and 1 for all the characters). Twenty-four responses were collected regarding the message that stood out from the story, these were categorised as: how to brush teeth/ tooth brushing generally $(n=13$, $54.2 \%)$, importance of oral health $(n=5,20.8 \%)$, not to be afraid of the dentist/ visit dentist regularly ( $n=4,16.7 \%)$, and to limit sugar $(n=2,8.3 \%)$.

\section{DISCUSSION}

This study set out to evaluate Kitten's First Tooth as a behavioural intervention to improve PSE primarily for twice daily tooth brushing and to a lesser extent for controlling sugar snacking as well as improving outcome expectancies for dental attendance and general attitudes towards prevention and tooth decay. An additional aim was to understand the acceptability of the intervention to parents. The pre-post evaluation using the OHBQ showed promising findings in terms of parental selfefficacy for tooth brushing as well as for outcome expectancy for dental attendance. 
However, the intervention failed to impact on parental self-efficacy for controlling sugar snacking or for parents' intention to control sugar snacking. The fact that behaviour change techniques targeting this behaviour were embedded less into the intervention may explain this but also provides additional support (through an inadvertent in-study comparison) for the effectiveness of the story book and DVD as the mechanism of change. Findings around the acceptability of the intervention to parents indicate that it was positively received.

This study is unique in that it used a novel approach (a storybook) with embedded behaviour change techniques to deliver oral health promotion to parents and children in two formats (book and DVD). The story was developed with embedded behaviour change techniques (Abraham \& Michie, 2008), which are easily identified and supports the operationalisation of theory-linked methods of behaviour change as well as ensuring greater clarity in reporting of the 'active ingredients' of the intervention as displayed in Table 1 earlier (Michie et al., 2013). This is in line with the recommendations of the WIDER group who promote clarity in reporting of behavioural interventions (Michie, Fixsen, Grimshaw, \& Eccles, 2009).

Despite the first taxonomy of behaviour change techniques having being published many years ago (Abraham \& Michie, 2008), relatively few interventions have been published where BCTs have been so carefully embedded. This may of course be due to the time necessary to develop, evaluate and publish behavioural interventions. Instead, there are many more studies that have utilised the BCT taxonomy to assess techniques present in existing studies (e.g. Briscoe \& Aboud, 2012; Webb \& Joseph, 2010; Golley, Hendrie, Slater, et al., 2011; Cooper, O’Malley, Elison, et al., 2013). 
One RCT however, conducted in Iran reports on an oral health promotion intervention directed at 12 year old children that was designed using Abraham and Michie's (2008) taxonomy (Yekaninejad et al., 2012). The intervention was delivered in classrooms by a health educationalist and was based on the Health Belief Model (Rosenstock, 1966). Self-reported tooth brushing and flossing behaviours and selfefficacy were significantly improved compared to the control group. The authors' report that a range of BCTs from Abraham and Michie's 2008 taxonomy were used (BCT1, 2, 5, 6, 7, 8, 9, 12, 13, 14) in the intervention itself. The advantage, for readers and reviewers, of this report is certainly the transparency in terms of the active components of this intervention. In contrast, a Cochrane review of primary schoolbased oral health programmes which included four studies attempted to code the interventions for BCTs. A smaller number and range of BCTs were found across these four studies (BCTs 1, 2, 8, 9, 12, 13) than were reported in Yekaninejad's (2012) study. While this may simply be because the interventions were not planned using the BCT taxonomy, it may well be because the reviewers had only limited access to the intervention materials, making it difficult to accurately describe the intervention. This lack of transparency in intervention reporting has implications both for the usefulness of evidence syntheses and the future development of oral health behaviour interventions.

In terms of the limitations of this study, there are several important lessons to communicate for future study development of this kind. Although a wide sampling frame was used for recruitment, the participants were self-selecting (in that they volunteered to participate) and it is possible that those who chose to participate in the study may have been more amenable to change. Additionally, due to the lack of randomised allocation of participants to study group, the possibility of confounding 
factors is likely thereby limiting generalizability. SES was considered to be a likely confounding factor so areas of study chosen were comparable in terms of their deprivation scores but this may also have implications for generalising to more affluent communities. Future studies should also include a measure of contamination which was absent here. It is possible given the lack of an active control in this study that attention to the intervention group on its own led to the findings. This limitation is addressed in a further study by this research group where an active control is being used as comparator in a randomised controlled trial of a series of storybooks aimed to increase parental self-efficacy to improve child oral health (Pine et al., 2016). Actual child tooth brushing and sugar consumption behaviours were not measured in this study, instead a general measure of attitudes towards these behaviours was collected. While there is good evidence to suggest that attitudes towards these behaviours is related to the behaviour being enacted (Adair et al., 2004; Huebner \& Riedy, 2010), future studies should include a measure of self-reported or actual frequency of these behaviours and should have a longer period of follow up. Caution should be exercised when interpreting the findings around intention to attend the dentist in the future. This is due to the fact that the items related to this outcome did not undergo rigorous validity testing and had lower reliability scores.

Regarding the fidelity of the intervention, little is known about how Kitten's First tooth was used in the home. This is something that should be measured in future studies, in particular, a process evaluation is recommended.

In conclusion, this evaluation of Kitten's First Tooth shows some promising findings indicating the potential utility and especially parent acceptability of story-based interventions for delivering oral health promotion to parents and their young children. 
However, it is important to note that this low intensity medium of BCT delivery may be more limited for behaviours or families who require additional support to facilitate change. That said, interventions delivered in this 'family-friendly' way, based on the findings presented here, may show promise to improve parental self-efficacy for child tooth brushing, behavioural intention for tooth brushing and dental attendance as well as outcome expectancies for dental attendance and attitudes around perceived seriousness of tooth decay. Further developments to improve the intervention and more robust evaluation such as through an RCT is required in order to understand the efficacy of this intervention and its generalisability across populations. 


\section{REFERENCES}

Abraham, C., \& Michie, S. (2008). A taxonomy of behavior change techniques used in interventions. Health Psychology, 27(3), 379-87.

Adair, P., Pine, C., \& Burnside, G. (2013). Analysis of health behaviour change interventions for preventing dental caries delivered in primary schools. Caries Research, 47(Suppl. 1), 2-12.

Adair, P., Pine, C., Burnside, G., \& et al. (2004). Familial and cultural perceptions and beliefs of oral hygiene and dietary practices among ethnically and socioeconomically diverse groups. Community Dental Health, 21(1), 102- 111.

Bernabe, E., Delgado-Angulo, E., \& Murasko, J. (2012). Family income and tooth decay in US children: does the association change with age? Caries Research, 46(3), 221-7.

Briscoe, C., \& Aboud, F. (2012). Behaviour change communication targeting four health behaviours in developing countries: a review of change techniques. Social Science \& Medicine, 75(4), 612-621.

Cooper, A., O’ Malley, L., Elison, S., Armstrong, R., Burnside, G., Adair, P., ... Pine, C. (2013). Primary school-based behavioural interventions for preventing caries (Review). Cochrane Database of Systematic Reviews, (5), 1-54. doi:10.1002/14651858.CD009378

Du, M., Luo, Y., \& Zeng, X. (2007). Caries in preschool children and its risk factors in 2 provinces in China. Quintessence International, 38(2), 143-151.

Dye, B., Arevalo, O., \& Vargas, C. (2010). Trends in paediatric dental caries by 
poverty status in the United States, 1988-1994 and 1999-2004. International Journal of Paediatric Dentistry, 20(2), 132-43.

Edelstein, B. (2006). The dental caries pandemic and disparities problem. BMC Oral Health, 6 Suppl 1, S2. doi:10.1186/1472-6831-6-S1-S2

Ferreira, S., Beria, J., \& Kramer, P. (2007). Dental caries in 0- to 5-year-old Brazilian children: prevalence, severity, and associated factors. International Journal of Paediatric Dentistry, 17(4), 289-96.

Golley, R. K., Hendrie, G. a, Slater, A., \& Corsini, N. (2011). Interventions that involve parents to improve children's weight-related nutrition intake and activity patterns - what nutrition and activity targets and behaviour change techniques are associated with intervention effectiveness? Obesity Reviews, 12(2), 114-30. doi:10.1111/j.1467-789X.2010.00745.X

Harris, R., Nicoll, A., Adair, P., \& Pine, C. (2004). Risk factors for dental caries in young children: a systematic review of the literature. Community Dental Health, 21(Suppl. 1), 71-85.

Huebner, C., \& Riedy, C. (2010). Behavioral determinants of brushing young children's teeth: implications for anticipatory guidance. Pediatric Dentistry, 32(1), 48-55.

IBM Corp. (2011). SPSS version 20. Armonk, NY.

Kay, E., \& Locker, D. (1998). A systematic review of the effectiveness of health promotion aimed at improving oral health. Community Dental Health, 15(3), $132-144$.

Kwan, S., Petersen, P.-E., Pine, C., \& Borutta, A. (2005). Health-promoting schools: 
an opportunity for oral health promotion. Bulletin of the World Health Organization, 83(9), 641-720.

Marinho, V., Higgins, J., Logan, S., \& Sheiham, A. (2009). Fluoride toothpastes for preventing dental caries in children and adolescents (Review). Cochrane Database of Systematic Reviews, (1), CD002278. doi:10.1002/14651858.CD002278

Michie, S. (2008). Designing and implementing behaviour change interventions to improve population health. Journal of Health Services Research \& Policy, 13 Suppl 3(October), 64-9. doi:10.1258/jhsrp.2008.008014

Michie, S., Fixsen, D., Grimshaw, J., \& Eccles, M. (2009). Specifying and reporting complex behaviour change interventions: the need for a scientific method. Implementation Science, 4(40), 1-6.

Michie, S., Richardson, M., Johnston, M., Abraham, C., Francis, J., Hardeman, W., ... Wood, C. (2013). The behavior change technique taxonomy (v1) of 93 hierarchically clustered techniques: building an international consensus for the reporting of behavior change interventions. Annals of Behavioral Medicine, 46(1), 81-95. doi:10.1007/s12160-013-9486-6

Nilsen, P., Roback, K., Broström, A., \& Ellström, P. (2012). Creatures of habit: accounting for the role of habit in implementation research on clinical behaviour change. Implement Science, 7(53).

O’Malley, L. (2013). The Development and Evaluation of a novel health promotion intervention (Kitten's First Tooth) to improve children's oral health in a deprived area of North West England. [unpublished thesis]. University of Salford. 
Pine, C., Adair, P., Robinson, L., Burnside, G., Moynihan, P., Wade, W., ... Henderson, M. (2016). The BBaRTS Healthy Teeth Behaviour Change Programme for preventing dental caries in primary school children: study protocol for a cluster randomised controlled trial. Trials, 17(103).

Prestwich, A., Sniehotta, F., Whittington, C., Dombrowski, S., Rogers, L., \& Michie, S. (2014). Does theory influence the effectiveness of health behavior interventions? Meta-analysis. Health Psychology, 33(5), 465-474.

Reisine, S., \& Psoter, W. (2001). Socioeconomic status and selected behavioral determinants as risk factors for dental caries. Journal of Dental Education, 65(10), 1009-16.

Rosenstock, I. (1966). Why people use health services. The Milbank Memorial Fund Quarterly, 83(4). doi:10.1111/j.1468-0009.2005.00425.x

Schwarzer, R., Antoniuk, A., \& Gholami, M. (2015). A brief intervention changing oral self- care, self- efficacy, and self- monitoring. British Journal of Health Psychology, 20(1), 56-67.

Sheeran, P., Harris, P., \& Epton, T. (2014). Does heightening risk appraisals change people’s intentions and behavior? A meta-analysis of experimental studies. Psychological Bulletin, 140(2), 511-543.

Tanaka, K., Miyake, Y., Sasaki, S., \& Hirota, Y. (2013). Socioeconomic status and risk of dental caries in Japanese preschool children: the Osaka Maternal and child health study. Journal of Public Health Dentistry, 73(3), 217-23.

Telford, C., Coulter, I., \& Murray, L. (2011). Exploring socioeconomic disparities in self-reported oral health among adolescents in California. Journal of the American Dental Association, 142(1), 70-78. 
Walsh, T., Worthington, H. V, Glenny, A., Appelbe, P., Marinho, V., \& Shi, X. (2010). Fluoride toothpastes of different concentrations for preventing dental caries in children and adolescents (Review). Cochrane Database of Systematic Reviews, (2).

Watt, R. (2007). From victim blaming to upstream action: tackling the social determinants of oral health inequalities. Community Dentistry and Oral Epidemiology, 35(1), 1-11. doi:10.1111/j.1600-0528.2007.00348.x

Webb, T., \& Joseph, J. (2010). Using the internet to promote health behavior change: a systematic review and meta-analysis of the impact of theoretical basis, use of behavior change. Journal of Medical Internet Research, 12(1), 1-18.

Yekaninejad, M. S., Eshraghian, M. R., Nourijelyani, K., Mohammad, K., Foroushani, A. R., Zayeri, F., ... Tarashi, M. (2012). Effect of a school-based oral health-education program on Iranian children: results from a group randomized trial. European Journal of Oral Sciences, 120(5), 429-37. doi:10.1111/j.1600-0722.2012.00993.x 